\title{
Microvibration on the Scalp as a Diagnostic Aid in Orthostatic Dysregulation
}

\author{
Katsuro IGarashi \\ Department of Pediatrics, Hirosaki University School of \\ Medicine, Hirosaki
}

IgarashI, K. Microvibration on the Scalp as a Diagnostic Aid in Orthostatic Dysregulation. Tohoku J. exp. Med., 1971, 105 (1), 11-17-The microvibration (MV) on the scalp of the parietal region in 23 healthy subjects and 16 patients with orthostatic dysregulation (O.D.) ranging from 9 to 11 years of age was recorded at rest in the supine position on the horizontally flat table and in the $20^{\circ}$ head up tilt position on the tilted flat table. The amplitude of the dominant vibration in the MV was smaller in O.D. patients than in healthy subjects in $20^{\circ}$ head up tilt position. This finding suggests that a decrease in cardiac output by tilting from the supine position to the $20^{\circ}$ head up tilt position is significantly larger in O.D. patients than in healthy subjects. - orthostatic dysregulation; microvibration; cardiac output

In the pediatric field Brück and Oltmann (1957) first reported vegetative dystonia which was characterized by the occurrence of dizziness on standing without known organic disorders mainly among children of the school ages. They called it orthostatic dysregulation (O.D.) in their report. The generating mechanism of this disorder has been considered by many investigators to be a circulatory disturbance causing a decrease in cardiac output, that is orthostatic hypotension.

In order to make the diagnosis of this disorder, many objective examinations have been applied, for example, the Schellong test (1933), the dye dilution method, the autonomic nervous function tests including pharmacological tests, that is, the mecholyl (Sawada, 1967), atropin or adrenalin test. In any case the examinations should not give pain or side-effects to the subjects. But they should be objective and be easily performed. Rohracher (1946) found a minor tremor on the body surface which was invisible to the naked eyes, having 7 to $13 \mathrm{cps}$ vibrations. He named it "microvibration (MV)"

The generating mechanism of the MV has been discussed thereafter by Sugano and Inanaga (1958) and Ozaki et al. (1962). Ozaki et al. (1969) recently reported a close relationship between the dominant vibration in the MV and the ballistocardiographic components when the subject is at rest. The present author (1970) tried to test a diagnostic aid of MV and recognized its usefulness.

Received for publication, February 1, 1971.

Director: Prof. Y. Izumi. 


\section{Methods and Materials}

The procedure for recording the MV is shown in Fig. 1. The MT-3T pickup equipped with an accelerative piezoelectric element (Nihon Kohden Kohgyo Co., Tokyo) was placed on the scalp of the parietal region. It was connected with a Multipurpose Polygraph RM 150 (Nihon Kohden Kohgyo Co., Tokyo) for recording the MV. The frequency characteristic of the pickup is 7 to $50 \mathrm{cps}$ and the linearity is within $-5 \mathrm{~dB}$. Piezoelectric element was held by a supporting spring. The external form which was $23 \mathrm{~mm}$ in diameter, $5.5 \mathrm{~mm}$ thick, and $3 \mathrm{~g}$ in weight, was a small cylinder. Fig. 2 shows the block diagram of the MV recording system. Mechanical vibration on the body surface was led by the pickup and

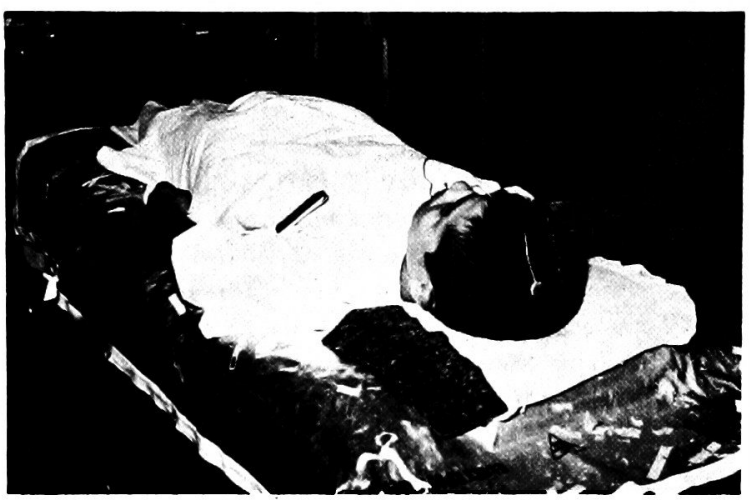

Fig. 1. Procedure for recording the MV. The MV at the parietal region is led by the MT$3 \mathrm{~T}$ pickup in the supine position.

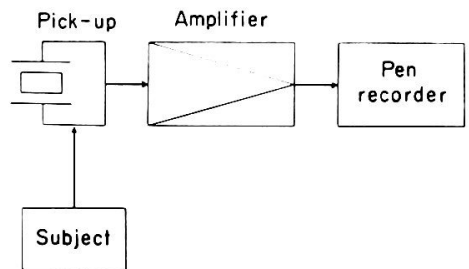

Fig. 2. Block diagram of recording system. Mechanical vibration on the body surface is led by the pickup and is transformed into electrical vibration.

The vibration is amplified by the amplifier and is recorded with a pen recorder.

transformed by it in electrical vibration. The vibration was amplified by the amplifier and recorded with a pen in the recorder.

There are two reasons why the pickup was placed on the scalp of the parietal region. The first reason is that the muscles at this site have few electromyographic components in the MV. The second one is the similarity of the waves in the MV at this site to those of the head-foot (H-F) displacement in the ballistocardiogram (BCG) when they are recorded simultaneously (Ozaki et al. 1970). The MV was recorded in 23 healthy subjects and in 16 O.D. patients. The male to female ratio was about $1: 1$. These examinees ranged from 9 to 11 years of age. In this study healthy subjects were selected among children without known organic disorders, especially without any symptoms of vegetative dystonia.

On the other hand, O.D. patients were selected according to the O.D. criteria which were decided by the orthostatic dysregulation research group in Japan (Takatsu and 


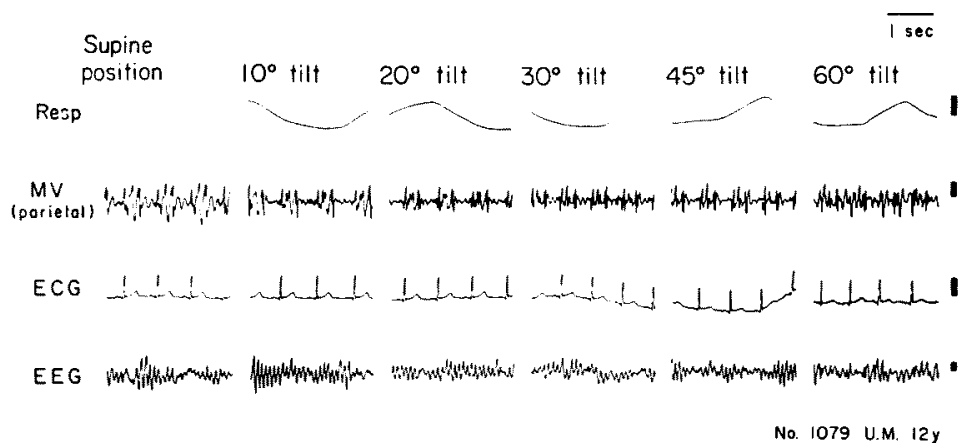

Fig. 3. The dominant amplitudes in the MV change at different degrees of the head-up tilt position.

EEG (occipto-parietal lead)

Resp: Respiratory movement curves. The top of the amplitude in the respiration curve shows the maximal inspiration and the bottom does the maximal expiration.

Ohkuni 1960). The room temperature had been kept between $26^{\circ}$ and $28^{\circ} \mathrm{C}$ during every recording. Every recording was performed between 2:00 and 5:00 P.M. Environmental conditions were maintained uniformly. The blood pressure of the subjects on standing and in the supine position was measured with a Riva-Rocci sphygmomanometer. The presence or absence of orthostatic proteinuria was noted by urinary screening test. Before the examination the subjects were informed of the testing method to remove unnecessary anxiety.

The MV on the scalp of the parietal region and the electrocardiogram (ECG) of the limb lead II were recorded simultaneously. They were recorded polygraphically. The subjects were placed at rest with closed eyes in the supine position on the tilt table. They were passively tilted from the horizontal to $20^{\circ}$ head-up tilt position. The effect degrees of head-up tilt on the main amplitude in the MV had been studied. The results were shown in Fig. 3 that when the subjects were placed in the head-up tilt positions at $10^{\circ}, 20^{\circ}, 30^{\circ}$, $45^{\circ}$ and $60^{\circ}$, the major change of the main amplitude in the MV occured in the $20^{\circ}$ head-up tilt position, and that there is little change in further tilt position. In the more than $45^{\circ}$ head-up tilt position, the baseline in the ECG drifted, or an electromyographic component was mixed with the ECG. The subjects felt that it was difficult to keep relaxed when the more than $45^{\circ}$ head-up tilt position was applied. As the amount of the response in the MV to various degrees not less than $20^{\circ}$ of tilt is almost equal, the subjects should be examined in the $20^{\circ}$ head-up tilt position. It took several seconds to change from the supine position to the $20^{\circ}$ head-up tilt position.

\section{Results}

The simultaneous records of the MV on the scalp of the parietal region and the ECG of the limb lead II are shown in Fig. 4. The distance between the higher and lower peaks of the same dominant vibration in the MV which corresponded well with the $R$ wave in the ECG was named the JK- segment, as shown in Fig. 5. The amplitude of the $\mathrm{JK}$ in the MV was measured in millimeters.

The average JK segment among the six successive JK segments was determined because the dominant vibrations have respiratory component. The rate in percentage of the value in the $20^{\circ}$ head-up tilt position (b) to that at rest in the supine 
Fig. 4. The simultaneous records of the MV and the ECG of the limb lead II.

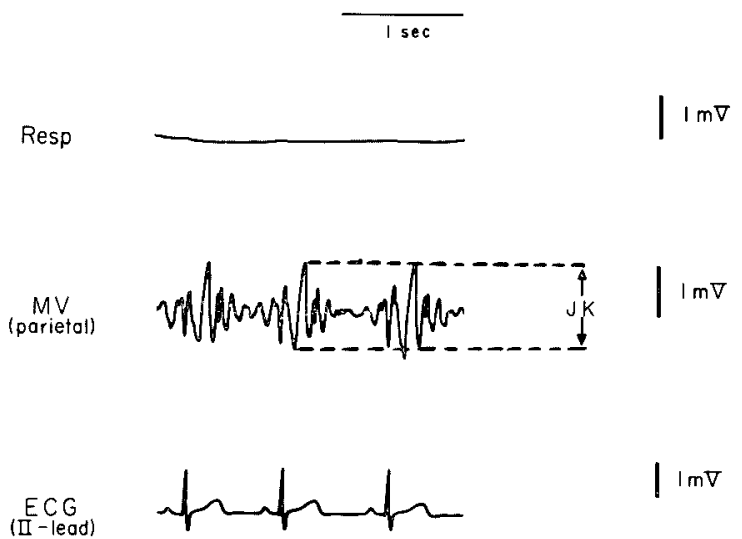

Fig. 5. The JK segment in the MV is measured in millimeters. Resp: Respiratory movement curve

TABLE 1. Control subjects having no O.D. symptoms I] O.D. symp. (-)

\begin{tabular}{r|l|c|c|c|c|c|c|c|c}
\hline No. & Name & $\begin{array}{c}\text { Supine } \\
\text { position } \\
(\mathrm{a})(\mathrm{mm})\end{array}$ & $\begin{array}{c}\text { Tilt } \\
20^{\circ} \\
(\mathrm{b})(\mathrm{mm})\end{array}$ & $\begin{array}{c}\mathrm{b} / \mathrm{a} \mathbf{1 0 0} \\
(\%)\end{array}$ & No. & Name & $\begin{array}{c}\text { Supine } \\
\text { position } \\
(\mathrm{a})(\mathrm{mm})\end{array}$ & $\begin{array}{c}\text { Tilt } \\
\text { position } \\
(\mathbf{b})(\mathbf{m m})\end{array}$ & $\begin{array}{c}\mathrm{b} / \mathrm{a} \times \mathbf{1 0 0} \\
(\%)\end{array}$ \\
\hline 1 & K.M & 20 & 18 & 90 & 13 & N.H & 16 & 15 & 93 \\
2 & S.S & 16 & 14 & 87 & 14 & I.T & 15 & 14 & 93 \\
3 & N.I & 18 & 18 & 100 & 15 & O.Y & 24 & 23 & 95 \\
4 & N.J & 20 & 19 & 95 & 16 & T.Y & 23 & 22 & 95 \\
5 & H.M & 19 & 19 & 100 & 17 & K.N & 22 & 20 & 91 \\
6 & K.M & 16 & 16 & 100 & 18 & N.I & 19 & 18 & 94 \\
7 & M.M & 17 & 17 & 100 & 19 & I.K & 36 & 32 & 88 \\
8 & S.T & 19 & 17 & 90 & 20 & S.M & 24 & 22 & 91 \\
9 & Y.S & 21 & 18 & 86 & 21 & S.H & 23 & 20 & 87 \\
10 & F.J & 17 & 15 & 89 & 22 & H.Y & 20 & 18 & 90 \\
11 & K.K & 24 & 23 & 96 & 23 & F.A & 28 & 26 & 92 \\
12 & K.M & 19 & 18 & 94 & & & & &
\end{tabular}


TABLE 2. Orthostatic dysregulation patients having O.D. symptoms II] O.D. symp. (+)

\begin{tabular}{|c|c|c|c|c|c|c|c|c|c|}
\hline No. & Name & $\begin{array}{l}\text { Supine } \\
\text { position } \\
\text { (a) (mm) }\end{array}$ & $\begin{array}{c}\text { Tilt } \\
20^{\circ} \\
\text { (b) }(\mathrm{mm})\end{array}$ & $\begin{array}{c}\mathrm{b} / \mathrm{a} \times 100 \\
(\%)\end{array}$ & No. & Name & $\begin{array}{l}\text { Supine } \\
\text { position } \\
\text { (a) }(\mathrm{mm})\end{array}$ & $\begin{array}{c}\text { Tilt } \\
20^{\circ} \\
\text { (b) }(\mathrm{mm})\end{array}$ & $\begin{array}{c}\mathrm{b} / \mathrm{a} \times \mathbf{1 0 0} \\
(\%)\end{array}$ \\
\hline 1 & F.K & 23 & 18 & 77 & 9 & F.M & 17 & 12 & 70 \\
\hline 2 & T.S & 22 & 20 & 90 & 10 & K.U & 17 & 12 & 70 \\
\hline 3 & K.S & 22 & 17 & 77 & 11 & Y.I & 17 & 16 & 94 \\
\hline 4 & S.K & 27 & 27 & 100 & 12 & I.M & 26 & 18 & 70 \\
\hline 5 & S.T & 32 & 25 & 78 & 13 & M.S & 18 & 13 & 72 \\
\hline 6 & N.A & 18 & 15 & 83 & 14 & H.S & 18 & 12 & 70 \\
\hline 7 & N.H & 24 & 20 & 83 & 15 & O.S & 19 & 16 & 84 \\
\hline 8 & M.S & 26 & 19 & 73 & 16 & K.Y & 20 & 12 & 60 \\
\hline
\end{tabular}

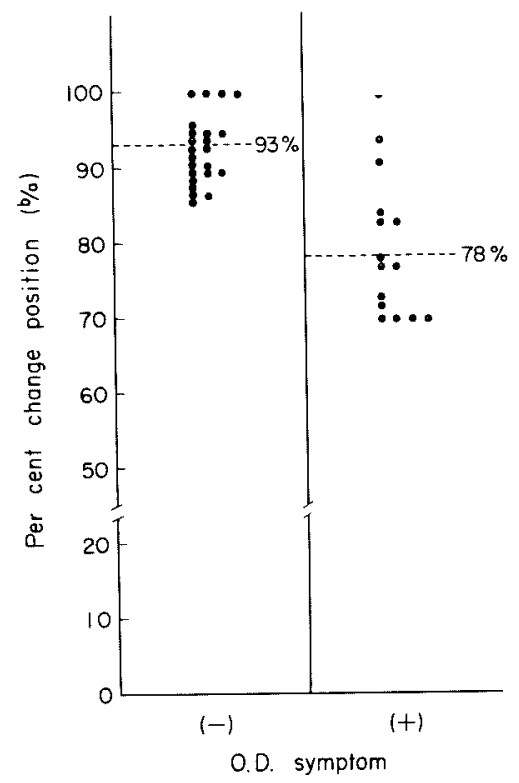

Fig. 6. The percentage of the value in the tilt position (b) to that at rest in the supine position (a) is calculated in every subject. (The average of the b/a ratio)

position (a) was calculated in every subject. The subjects were classified to the following two groups.

I) Control having no O.D. symptoms (Table 1).

II) Patients having O.D. symptoms (Table 2).

Generally speaking, the dominant amplitudes in the MV are smaller in the $20^{\circ}$ head-up tilt position than in the supine position. The range of the $\mathrm{b} / \mathrm{a}$ ratio is from 86 to $100 \%$ in group I, and from 60 to $100 \%$ in group II. In Fig. 6, the percentage values in all cases were plotted. The average of the b/a ratio was $93 \%$ in group I and $78 \%$ in group II. The difference in the average ratio of the b/a between in healthy subjects and in O.D. patients was considered to be statistically significant. 


\section{Discussion}

It is well known that cardiac output decreases $19 \sim 23 \%$ in normal subjects in changing from the supine to tilt position. Starr (1967) mentioned that the IJ segment in the BCG corresponded well with cardiac output or cardiac force of the intact heart. The size of the IJ segment in the BCG, in other words, presented the relative cardiac output or cardiac force in their report. But Ozaki et al. (1970) recently mentioned that the dominant vibration in the MV corresponded with the IJ segment of the HF force in the BCG by the use of von Wittern's low frequency table modified by Nihon Kohden Kohgyo Co., Tokyo (Sasamoto and Kitada 1955). They suggested that the dominant vibration in the MV corresponded well with cardiac output or cardiac force.

In this study the difference in relative cardiac output in the tilt position between healthy subjects and O.D. patients was investigated by evaluating the dominant segments in the MV. Nagayama et al. (1968) mentioned that a greater decrease in cardiac output was observed in patients with dizziness than those without dizziness on standing by means of the dye-dilution method.

In this study some of the healthy subjects showed $86 \%$ in the b/a ratio and some of the O.D. patients, $100 \%$. This discrepancy may have something to do with the sensitivity of the subjects. The dominant vibration in the MV may also have some relation to peripheral vascular resistance, the state of emotion or the muscle tone. Hayashi et al. (1967) reported that there was little difference in the decrease in cardiac output in the tilt position between healthy subjects and O.D. patients by means of the dye-dilution method. In their study both increase in peripheral vasoconstriction and decrease in mean arterial pressure might have equally interacted in O.D. patients. Further studies should be performed to clarify the relation between hypotension and increases in peripheral vascular resistance caused by a decrease in cardiac output in O.D. patients.

It is very interesting to note how hemodynamics is concerned with O.D.. The study of the MV in O.D. may be considered to give an important clue to the hemodynamics in O.D. Advantages in recording the MV are as follows: 1) painless, 2) non-operative, and 3) easy procedure by the use of a standard electrocardiograph.

\section{SUMmary}

1) The MV on the scalp of the parietal region in 23 healthy subjects and 16 O.D. patients ranging from 9 to 11 years of age was recorded at rest in the supine position.

2) The rate in percentage of the value in the tilt position (b) to that at rest in the supine position (a) was calculated in every subject. The average of the b/a ratio was $93 \%$ in the healthy subjects and $78 \%$ in the O.D. patients. A statistically significant difference was observed between these two groups.

3) The above results might be considered mainly due to a transitory greater 
decrease in cardiac output in O.D. patients in $20^{\circ}$ head-up tilt position from the supine position at rest than that in healthy subjects.

4) The other factors affecting the results may be considered to be an increase in peripheral vascular resistance, the state of emotion, the sensitivity of the subject, etc. O.D..

5) The study of the MV may give an important clue to the hemorlynamics in

6) A statistically significant difference in the average dominant amplitude in the MV between the healthy subjects and the O.D. patients was obtained. Therefore the MV can be used as a diagnostic aid in O.D.

\section{Acknowledgment}

I am indebted to Prof. Y. Izumi, Department of Pediatrics for his criticism, to Prof. T. Ozaki, Department of Physiology for his advice, and to Mr. I. Sato, Central Clinical Laboratory, Hirosaki University School of Medicine for his technical assistance.

\section{References}

1) Brück, K. \& Oltmann, D. Zur Diagnostik und Therapie der orthostatischen Dysregulation des Kindes. Prüfung des Präparates Carnigen. Mschr. Kinderh., 1957, 105, 7-12.

2) Hayashi, M., Takarada, M., Chinen, M. \& Ohnishi, A. On the dye-dilution curve of the OD patients. Clinical Report (Jap.), 1967, 8, 5-9.

3) Igarashi, K. Application of microvibration on body surface in diagnosis of orthostatic dysregulation. Tohoku J. exp. Med., 1970, 102, 207-208.

4) Nagayama, T., Hirose, M. \& Uryu, K. On the hemodynamics on the standing position by the dye-dilution method. Clinical Report (Jap.), 1968, 9, 4-7.

5) Ozaki, T., Igarashi, K., Sasaki, S. \& Takahashi, H. The microvibration of the body surface related to the heart beat in complete A-V block. Tohoku J. exp. Med., 1969, 99, 303-305.

6) Ozaki, T., Sasaki, S. \& Igarashi, K. Ballistocardiography simplified by recording microvibration of the skin surface of the head. Tohoku J. exp. Med., 1970, 102, 99-100.

7) Ozaki, T., Sato, K., Mimura, K., Honda, N., Teramoto, S. \& Kitazima, K. Some observations on minor tremors related to heart beat. Jap. J. Physiol., 1962, 12, 484-493.

8) Rohracher, H. Schwingungen in menschlichen Organismus. Anz. phil. hist. Klasse Osterr. Akad. Wiss., 1946, 18, 230-245.

9) Sasamoto, H. \& Kitada, S. Ballistocardiography (Jap.), Igaku Shoin, Tokyo, 1955.

10) Sawada, S. Mecholyl test in children. Clinical Report (Jap.), 1967, 8, 14-16.

11) Schellong, F. \& Heinemeier, M. Über die Kreislaufregulation in aufrechter Körperstellung und ihre Störungen. Z. ges. exp. Med., 1933, 89, 49-60.

12) Starr, I. Ballistocardiography in cardiovascular research, North-Holland, Amsterdam, 1967.

13) Sugano, H. \& Inanaga, K. On the mechanism of minor tremor. Brain, Nerve (Jap.), 1958, 10, 769-780.

14) Takatsu, T. \& Ohkuni, M. Criteria of orthostatic dysregulation. Clinical Report (Jap.), 1960, 1, 2-3. 